\title{
Adsorption and desorption performance of benzene over hierarchically structured carbon-silica aerogel composites
}

\author{
Baojuan Dou, Jinjun Li, Yufei Wang, Hailin Wang, Chunyan Ma*, Zhengping Hao** \\ Department of Environmental Nano-Materials, Research Center for Eco-Environmental Sciences, Chinese Academy of Sciences, Beijing 100085, PR China
}

\section{A R T I C L E I N F O}

\section{Article history:}

Received 9 March 2011

Received in revised form 2 September 2011

Accepted 5 September 2011

Available online 10 September 2011

\section{Keywords:}

Carbon-silica aerogel composites

VOCs

Adsorption and desorption

Micro/mesoporous structure

\begin{abstract}
A B S T R A C T
Hierarchically structured carbon-silica aerogel (CSA) composites were synthesized from cheap water glass precursors and granulated activated carbon via a post-synthesis surface modification with trimethylchlorosilane (TMCS) and a low-cost ambient pressure drying procedure. The resultant CSA composites possess micro/mesoporous structure and hydrophobic surface. The adsorption and desorption performance of benzene on carbon-silica aerogel composite (CSA-2) under static and dynamic conditions were investigated, comparing with pure silica aerogel (CSA-0) and microporous activated carbon (AC). It was found that CSA-2 has high affinity towards aromatic molecules and fast adsorption kinetics. Excellent performance of dynamic adsorption and desorption observed on CSA-2 is related to its higher adsorption capacity than CSA-0 and less mass transfer resistance than AC, arising from the well-developed microporosity and open foam mesostructure in the CSA composites.
\end{abstract}

(ㄷ) 2011 Elsevier B.V. All rights reserved.

\section{Introduction}

From an environmental point of view, it is necessary to control volatile organic compounds (VOCs) emissions, because such compounds are hazardous to human health, contributing to seriously environmental problems such as the destruction of the ozone layer, photochemical smog and global warming [1,2]. Adsorption technologies for controlling VOC emissions have been recognized as preferred strategies, especially in cases where the captured organic pollutants have alternative uses [3]. Among various adsorbents, activated carbon is the most widely used for VOC adsorption due to its low cost and well-developed microporosity which ensures excellent adsorption capacity [4]. However, serious diffusion restrictions imposed by micropores in activated carbon tend to inhibit its ability to adsorb large VOC molecules. Besides, molecules adsorbed in the micropores of activated carbon are strongly held by adsorption forces [5], hence, it is hard for the adsorbent to be regenerated. It is obvious that the regeneration of saturated adsorbents is a critical factor that should be considered in the adsorbent selection process [6]. Moreover, when it is used under various operational conditions, activated carbon frequently encounters problems, such as fire risk, pore clogging, hygroscopicity, lower selectivity and limited modification flexibility $[7,8]$.

Silica aerogels, prepared by sol-gel processing and subsequent solvent extraction, have large surface area, high porosity and

\footnotetext{
* Corresponding author. Tel.: +86 10 62849194; fax: +86 1062849194 .

** Corresponding author. Tel.: +8610 62923564; fax: +861062923564.

E-mail addresses: cyma@rcees.ac.cn (C. Ma), zpinghao@rcees.ac.cn (Z. Hao).
}

extremely low densities due to the open pore structure of the mesopores [9]. The unique pore structure permits easy regeneration of the silica aerogels $[10,11]$. In addition, silica aerogel surface can be chemically modified to improve the hydrophobicity and selectivity for target specific compounds, like VOCs [12]. El Rassy et al. [13] showed that the hydrophobicity of silica aerogel surface was enhanced through the modification with methyltrimethoxylsilane. Standeker et al. [11] found that silica aerogels modified with methyltrimethoxysilane or trimethylethoxysilane exhibited high adsorption capacities for toxic organic compounds from water, which were from 15 to 400 times higher as compared with granulated active carbon. Traditional silica aerogels preparation approaches involve supercritical drying process to avoid capillary stress and related drying shrinkage, whereas the supercritical drying process is energy intensive, expensive and dangerous [14]. To overcome these disadvantages of traditional supercritical aerogel process, a new ambient pressure drying process technique has been developed, making the manufacture and application of silica aerogels in large scale possible [15]. Moreover, the fragility and brittleness of silica aerogels could limit their applications to some extent in various fields $[9,16]$. Therefore, it is expected that the composite materials derived from the combination of activated carbons and silica aerogels, namely, carbon-silica aerogel composites, may improve the adsorption and desorption performance of the adsorbent and thereby reduce the cost.

Carbon-silica aerogel composites have potential applications in various fields, such as catalyst supports $[17,18]$, adsorbents for groundwater treatment [12] and electroconductive materials, etc. [19]. However, there is limited information in literature related to adsorption and desorption properties of carbon-silica aerogel 
composites. Coleman et al. [12] found that a cost-effective granulated activated carbon (GAC)-aerogel composite was superior in removing uranium from a stock solution compared with GAC alone. To the best of our knowledge, there has been no report on VOC emission controlling by using carbon-silica aerogel composites as adsorbents, especially in terms of adsorption and desorption kinetics which might play fundamental roles in the application of adsorbent for real situations.

In this work, hierarchically structured carbon-silica aerogel composites were synthesized by adding powered activated carbon to the silica sol just before gelation. In order to reduce the CSA composites cost, cheap water glass was used as precursors to synthesize silica aerogels. After solvent exchange and surface modification, the wet gels of composites were subsequently dried by a low-cost technique of ambient pressure drying. Adsorption and desorption performance as well as the corresponding kinetics of VOCs for carbon-silica aerogel composites were intensively studied, comparing with pure silica aerogels and microporous activated carbon. The investigations of adsorption and desorption for VOCs were carried out under both static and dynamic conditions by a digital microbalance and a flow adsorption measurement. We believe that the obtained CSA composites could be effective adsorbents for VOC emission controlling.

\section{Experimental}

\subsection{Material synthesis}

Silica sols were prepared by using cheap water glass $\left(\mathrm{Be}^{0}=40\right.$, $\mathrm{Na}_{2}: \mathrm{SiO}_{2}$ molar ratio=1:3.3, Beijing Chemical Works) as precursors. In a typical synthesis, $10 \mathrm{~mL}$ of water glass was diluted by deionized water with volume ratio of $1: 4$ and then mixed with strongly acidic type ion exchange resin so as to remove $\mathrm{Na}^{+}$ions. After stirring the mixture for $10 \mathrm{~min}, \mathrm{pH}$ of the solution was decreased in the range of $2-3$, resulting in the formation of silicic acid. In the subsequent step, the base catalyst $\left(\mathrm{NH}_{4} \mathrm{OH}, 1 \mathrm{M}\right)$ was added drop by drop to raise $\mathrm{pH}$ to 5 with constant stirring. Waiting until the silica sol is just about to gel, $1 \mathrm{~g}$ of powered activated carbon (BN-09, <60 mesh, Ningxia BENNIU Activated Carbon Works) was added, followed by stirring for some minutes and keeping the colloidal mixture for gelation at room temperature. After aging for $3 \mathrm{~h}$, water in the composite gels was exchanged with ethanol for three times in $36 \mathrm{~h}$. To prevent the reverse reaction of surface modification [20], ethanol was exchanged with n-hexane for three times in $36 \mathrm{~h}$. The gels were modified with $20 \%$ trimethylchlorosilane (TMCS) in n-hexane for $24 \mathrm{~h}$ and then the unreacted TMCS was washed with n-hexane for two times in $24 \mathrm{~h}$. Finally, the wet gels of composites were dried under ambient pressure at $60^{\circ} \mathrm{C}, 80^{\circ} \mathrm{C}$, $120^{\circ} \mathrm{C}$ and $180^{\circ} \mathrm{C}$ for $6 \mathrm{~h}$, respectively. The obtained CSA composites were denoted as CSA- $x$, where $x$ is referred to the mass fraction of activated carbon in wet gels.

\subsection{Characterizations and measurements}

Nitrogen adsorption and desorption measurements on CSA composites were conducted at liquid nitrogen temperature $\left(-196^{\circ} \mathrm{C}\right)$ by using NOVA 1200 gas sorption analyzer. Each sample was degassed under vacuum condition at $120^{\circ} \mathrm{C}$ for $18 \mathrm{~h}$ prior to the measurement. The BET specific surface area was calculated by using adsorption data at relative pressure $\left(P / P_{0}\right)$ of $0.05-0.25$, and the total pore volume was estimated from the amount adsorbed at a relative pressure of about 0.99 . Pore size distributions (PSD) of CSA composites were calculated from the analysis of desorption branch of the isotherm, by using Barrett-Joyner-Halenda (BJH) algorithm. Fourier transform infrared (FT-IR) spectroscopy was measured by the $\mathrm{KBr}$ method recorded on a Bruker Tensor 27, scanned from 4000 to $600 \mathrm{~cm}^{-1}$. The thermogravimetric analysis (TGA) of adsorbents was performed on a TG/DTA analyzer (Setaram, Labsys). The heating rate was $10^{\circ} \mathrm{C} \mathrm{min}^{-1}$ from 40 to $700^{\circ} \mathrm{C}$ under an airflow of $30 \mathrm{~mL} \mathrm{~min}^{-1}$.

\subsection{Static adsorption and desorption measurements}

The static adsorption and desorption equilibrium measurements for CSA composites were recorded by using an Intelligent Gravimetric Analyzer (Model IGA-002, Hiden Isochema Instrument) with a sensitivity of $0.1 \mu \mathrm{g}$. The apparatus had an ultrahigh vacuum system allowing isotherms and the corresponding kinetics to be determined by setting pressure steps. For each pressure increment or decrement, weight changes due to adsorption or desorption were used to calculate kinetic parameters. Before the measurement, each sample was degassed at $110^{\circ} \mathrm{C}$ over night.

\subsection{Dynamic adsorption and desorption measurements}

The investigations of dynamic adsorption and desorption of VOCs for CSA composites were carried out by a flow method on an experimental set-up [21]. After degassing at $110^{\circ} \mathrm{C}$ for $24 \mathrm{~h}$, about $1 \mathrm{~g}$ of adsorbent (40-60 mesh) was packed into the adsorption bed. The adsorption measurement was performed under both dry and wet conditions. The concentration of benzene was controlled at $700 \mathrm{ppm}$ and the total flow rate was $100 \mathrm{~mL} \mathrm{~min}^{-1}$. To observe the effects of water vapor on adsorption behaviors of CSA composites, test gases consisted of nitrogen, $700 \mathrm{ppm}$ of benzene under the relative humidity (RH) of $18 \%$, were passed through the adsorption bed. After samples were saturated with benzene vapor, the benzene saturator was bypassed to start purging samples with nitrogen flow at room temperature. In addition, dynamic desorption properties of adsorbents were investigated by temperature programmed desorption (TPD) technique. The concentration of benzene before and after the adsorption process was tested by using gas chromatograph (GC) equipped with a flame ionization detector.

\section{Results and discussion}

\subsection{Characterization of carbon-silica aerogel composites}

Fig. 1 shows the nitrogen adsorption and desorption isotherms of CSA composites at $-196^{\circ} \mathrm{C}$ and the corresponding pore size distributions obtained by the $\mathrm{BJH}$ method. For comparison, pure silica aerogel CSA-0 and commercial AC were studied. As can be seen in Fig. 1a, the shape of adsorption isotherms for all CSA samples can be considered as a combination of type I and type IV, according to the IUPAC classification [22]. The steep increase of adsorbed amount at low relative pressure $\left(P / P_{0}<0.1\right)$ indicates the presence of micropores in these materials. At intermediate $P / P_{0}$, a capillary condensation step and an H2-type hysteresis loop was observed, suggesting the formation of worm-like mesopores during the synthesis process of CSA composites [23]. However, the adsorption isotherm for AC is of type I, which is typical for microporous activated carbon. With increasing mass fraction of activated carbon, the microporosity of CSA composites increases while the total pore volume decreases (see Table 1 ). The nitrogen adsorption and desorption results provide evidence for the existence of both micropores and mesopores in CSA composites.

The FT-IR spectrum of modified silica aerogel CSA-0 and carbon-silica aerogel composite CSA-2 is shown in Fig. 2. The FT-IR spectrum represents a broad band at around $3500 \mathrm{~cm}^{-1}$ and a peak at around $1600 \mathrm{~cm}^{-1}$, which can be attributed to O-H groups [24]. The peaks at around 1100 and $800 \mathrm{~cm}^{-1}$ are due to asymmetric and symmetric modes of $\mathrm{SiO}_{2}$ [25]. The peaks at 2980 and $1450 \mathrm{~cm}^{-1}$ 

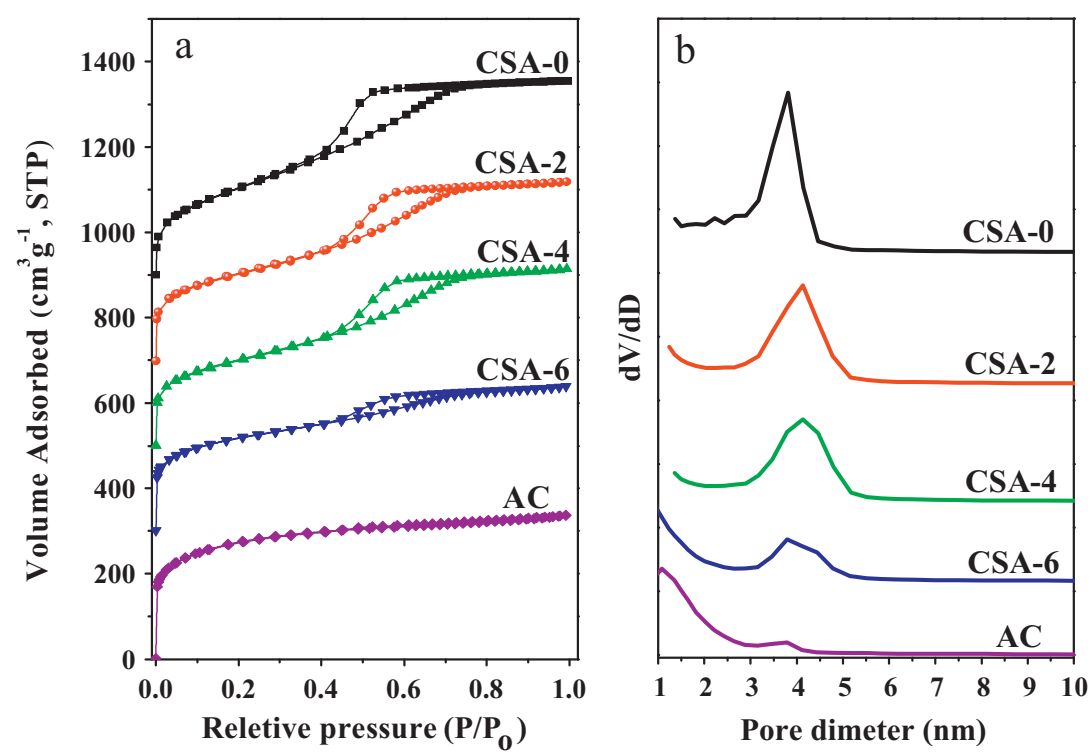

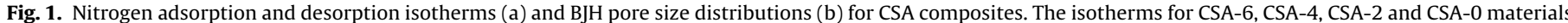
are shifted by $300,500,700$ and $900 \mathrm{~cm}^{3} \mathrm{~g}^{-1} \mathrm{STP}$, respectively.

Table 1

Textural properties of carbon-silica aerogel composites.

\begin{tabular}{|c|c|c|c|c|c|}
\hline Sample & $\begin{array}{l}\text { BET surface } \\
\text { area }\left(\mathrm{m}^{2} \mathrm{~g}^{-1}\right)\end{array}$ & $\begin{array}{l}\text { Average pore } \\
\text { diameter }^{\mathrm{a}}(\mathrm{nm})\end{array}$ & $\begin{array}{l}\text { Total pore volume } \\
\left(\mathrm{cm}^{3} \mathrm{~g}^{-1}\right)\end{array}$ & $\begin{array}{l}\text { Micropore volume } \\
\left(\mathrm{cm}^{3} \mathrm{~g}^{-1}\right)\end{array}$ & $\begin{array}{l}\text { Micropore area } \\
\left(\mathrm{m}^{2} \mathrm{~g}^{-1}\right)\end{array}$ \\
\hline CSA-0 & 726 & 3.9 & 0.71 & - & - \\
\hline CSA-2 & 727 & 3.6 & 0.66 & 0.05 & 102 \\
\hline CSA-4 & 710 & 3.6 & 0.64 & 0.05 & 110 \\
\hline CSA-6 & 758 & 2.8 & 0.53 & 0.18 & 393 \\
\hline $\mathrm{AC}$ & 936 & 2.2 & 0.52 & 0.33 & 715 \\
\hline
\end{tabular}

a Calculated using the Barrett-Joyner-Halenda (BJH) model based on the desorption branch of the isotherm.

are assigned to $\mathrm{C}-\mathrm{H}$ bonds, while the peak at $840 \mathrm{~cm}^{-1}$ is attributed to $\mathrm{Si}-\mathrm{C}$ bond. FT-IR results clearly confirm that methyl groups are covalently anchored onto the CSA composite surface.

The thermal stability of carbon-silica aerogel composites was observed by TGA-DTA analysis, as shown in Fig. S1 (Supporting Information). The weight loss at temperature lower than $150^{\circ} \mathrm{C}$ is attributed to the loss of adsorbed water and the evaporation of residual organic compounds. The weight loss at temperature higher than $400{ }^{\circ} \mathrm{C}$ is due to the oxidation of the $-\mathrm{CH}_{3}$ on the surface of adsorbents developed by surface modification with TMCS (Fig. S1a),

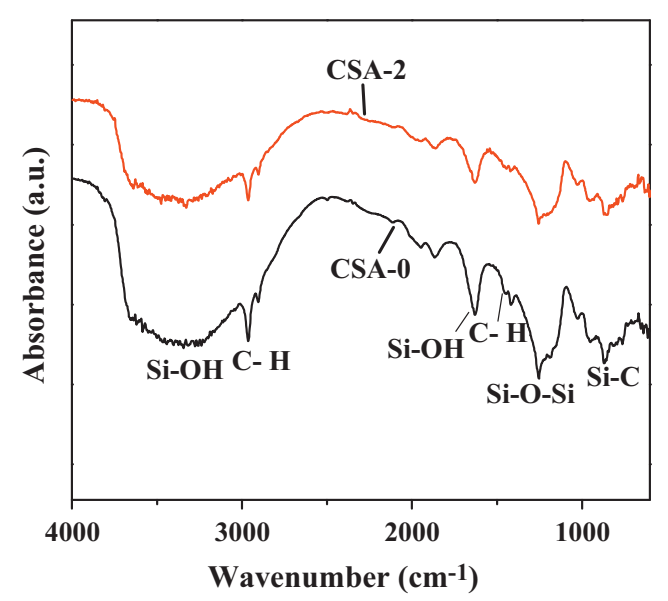

Fig. 2. FT-IR spectra of patterns for CSA-0 and CSA-2 materials. implying that the retention of surface hydrophobicity can be up to $400^{\circ} \mathrm{C}$.

\subsection{Static adsorption and desorption behaviors}

The carbon-silica aerogel composite CSA-2 with developed microporosity and open mesostructure was adopted here as a representative sample to estimate its adsorption and desorption properties for VOCs, comparing with pure silica aerogel CSA-0 and microporous AC. Fig. 3 shows the adsorption and desorption isotherms of benzene on CSA-0 (Fig. 3a), CSA-2 (Fig. 3b) and AC (Fig. 3c) at temperatures of 25,35 , and $45^{\circ} \mathrm{C}$, respectively. The shapes of adsorption and desorption isotherms of benzene for all the samples are similar to the nitrogen isotherms. It is found that the amount of benzene adsorbed at low pressure increases in the order of $\mathrm{AC}>\mathrm{CSA}-2>\mathrm{CSA}-0$, with the augmentation in microporosities of the materials. The adsorption in micropores at low pressure is a direct consequence of the overlap in the adsorption field from adjacent walls of micropores. In comparison with AC (Fig. 3c), the adsorption isotherms of benzene for both CSA-0 (Fig. 3a) and CSA-2 (Fig. 3b) exhibit capillary condensation steps which is attributed to the presence of mesopores in these materials. Therefore, the adsorption isotherms of benzene on CSA- 0 and CSA- 2 exhibit a combination of microporous and mesoporous adsorptive behavior. As shown in Table 2, the equilibrium adsorption capacity of benzene for CSA-2 $\left(5.06 \mathrm{mmol} \mathrm{g}^{-1}\right)$ is higher than that for microporous AC $\left(4.37 \mathrm{mmol} \mathrm{g}^{-1}\right)$ at relatively high temperature of $45^{\circ} \mathrm{C}$, and the equilibrium adsorption capacity changes in the order of CSA $-2>$ CSA- $0>$ AC. This result can be explained by the fact that 
Table 2

Equilibrium adsorption capacities $\mathrm{Q}^{\mathrm{e}}\left(\mathrm{mmol} \mathrm{g}^{-1}\right)$ and Henry constants $K\left(10^{-5} \mathrm{~mol} \mathrm{~g}^{-1} \mathrm{~Pa}^{-1}\right)$ of benzene on CSA-0, CSA-2 and AC at different temperatures.

\begin{tabular}{|c|c|c|c|c|c|c|}
\hline \multirow[t]{2}{*}{ Samples } & \multicolumn{3}{|c|}{ Equilibrium adsorption capacities $Q^{\mathrm{e}}\left(\mathrm{mmol} \mathrm{g}^{-1}\right)$} & \multicolumn{3}{|c|}{ Henry constants $K\left(10^{-5} \mathrm{~mol} \mathrm{~g}^{-1} \mathrm{~Pa}^{-1}\right)$} \\
\hline & $25^{\circ} \mathrm{C}$ & $35^{\circ} \mathrm{C}$ & $45^{\circ} \mathrm{C}$ & $25^{\circ} \mathrm{C}$ & $35^{\circ} \mathrm{C}$ & $45^{\circ} \mathrm{C}$ \\
\hline CSA-0 & 7.42 & 7.17 & 7.29 & 0.32 & 0.28 & 0.20 \\
\hline CSA-2 & 5.18 & 5.20 & 5.06 & 0.40 & 0.37 & 0.22 \\
\hline$A C$ & 4.82 & 4.74 & 4.37 & 0.94 & 0.77 & 0.29 \\
\hline
\end{tabular}

the static VOC adsorption capacity is proportional to the total pore volume, in accordance with the literature [26].

The Henry constants, which reflect adsorption affinity in the line region of the adsorption isotherm, can be estimated from the adsorption date at very low pressure ( $P<3$ mbar), where the interaction between adsorbed molecules may be neglected and only interactions between adsorbed molecules and the surface remain [27]. The Henry constants of benzene adsorption at different temperatures are listed in Table 2. As expected, Henry constants of all the samples decrease with the increase of temperature. At the same temperature, Henry constants increase in the order of AC $>$ CSA-2 $>$ CSA-0, with the augmentation in microporosities of the CSA composites. This result can be explained by strong adsorption energy in micropores [21]. In the micropores, due to dispersion interactions, field superposition from the close separated opposing pore walls enhances the physical adsorption behavior. In addition, the isosteric heat of adsorption represents the strength of the interaction between adsorbent and adsorbate, hence it can be used to gauge the compatibility between them. Additionally, the isosteric
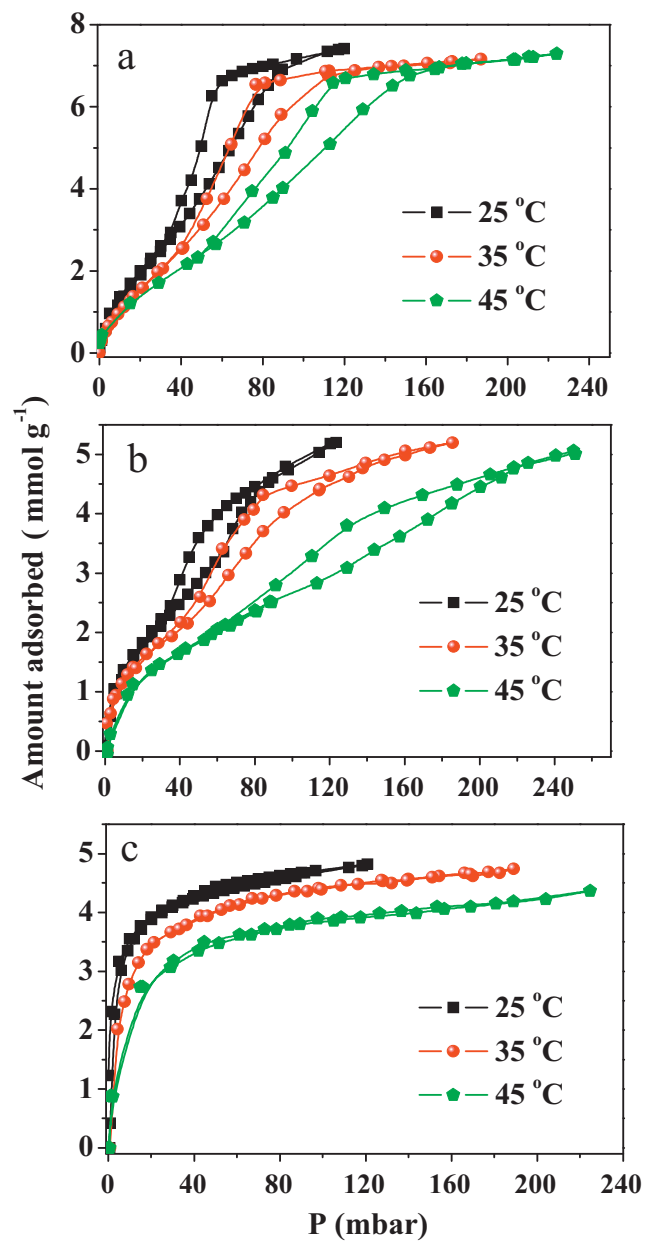

Fig. 3. Adsorption and desorption isotherms of benzene on CSA-0 (a), CSA-2 (b) and AC (c) materials at different temperatures. heat of adsorption ( $\Delta H_{\mathrm{ads}}$ ) can be calculated from the measured adsorption equilibrium data at different temperatures by using the Clausius-Clapeyron equation [28]. The adsorption isosteric heat for adsorption of benzene versus the loading on CSA-0, CSA-2 and AC is shown in Fig. S2 (Supporting Information). For all the samples, the isosteric heat of adsorption reaches a constant value after an initial sharp decrease. This decrease may be attributed to the heterogeneity of adsorption sites [29]. Afterwards, owing to the confinement effect, the adsorption heat decreases gradually with the increase in adsorbate loading and then gets close to the heat of liquefaction in bulk liquid phase.

\subsection{Adsorption and desorption kinetics}

Adsorption and desorption kinetics are of fundamental importance in actual applications [30]. The mass relaxation curve cursed by pressure increment or decrement can be used to calculate the adsorption and desorption kinetic parameters. Studies found that the linear driving force (LDF) model was followed in most cases of the adsorption kinetics of various gases/vapors on activated carbons [30], metal organic framework materials [31], carbon molecular sieves [32] and silica mesoporous materials [33]. The LDF model for adsorption is described by the following equation:

$\frac{M_{t}}{M_{e}}=1-e^{-k t}$

where $M_{t}$ is the uptake at time $t, M_{e}$ is the equilibrium uptake for the given pressure increment, and $k$ is the rate constant. The corresponding LDF model for desorption is described by the equation:

$\frac{M_{t}}{M_{e}}=e^{-k t}-1$

where $M_{e}$ is the amount desorbed at equilibrium for the given pressure decrement and $M_{t}$ is the amount desorbed at time $t$ [30].

Fig. 4 shows typical graphs of $M_{t} / M_{e}$ versus time for adsorption and desorption of benzene and the corresponding fits for the LDF model on CSA-0, CSA-2 and AC, respectively. It is evident that adsorption kinetics for the three adsorbents obeys the LDF model, which indicates that the diffusion through a barrier is the rate determining step. The barrier is either due to constrictions in the porosity with similar size to that of benzene or a surface diffusion barrier [33]. Obviously, the desorption kinetics also obeys the LDF model, similar to the adsorption ones.

A comparison of the variation of adsorption and desorption rate constants of benzene with relative pressure at $35^{\circ} \mathrm{C}$ on CSA-0, CSA-2 and AC is shown in Fig. 5. In the initial uptake region, the adsorption rate constants for CSA-0 (Fig. 5a) and CSA-2 (Fig. 5b) are significantly faster than those for AC (Fig. 5c). This observation can be attributed to the fact that the presence of open mesoporous structure in CSA- 2 and CSA-0 allows high accessibility of adsorptives. For all the samples, the adsorption rate constants initially decrease to a plateau (observed at $P / P_{0} \sim 0.4$ ) before increasing with relative pressure. The decrease in rate constants can be attributed to the development of benzene molecular clusters in micropores of adsorbents. On the other hand, the increase in rate constants when the relative pressure is greater than 0.6 is probably related to the growth of the benzene molecular clusters filling the 

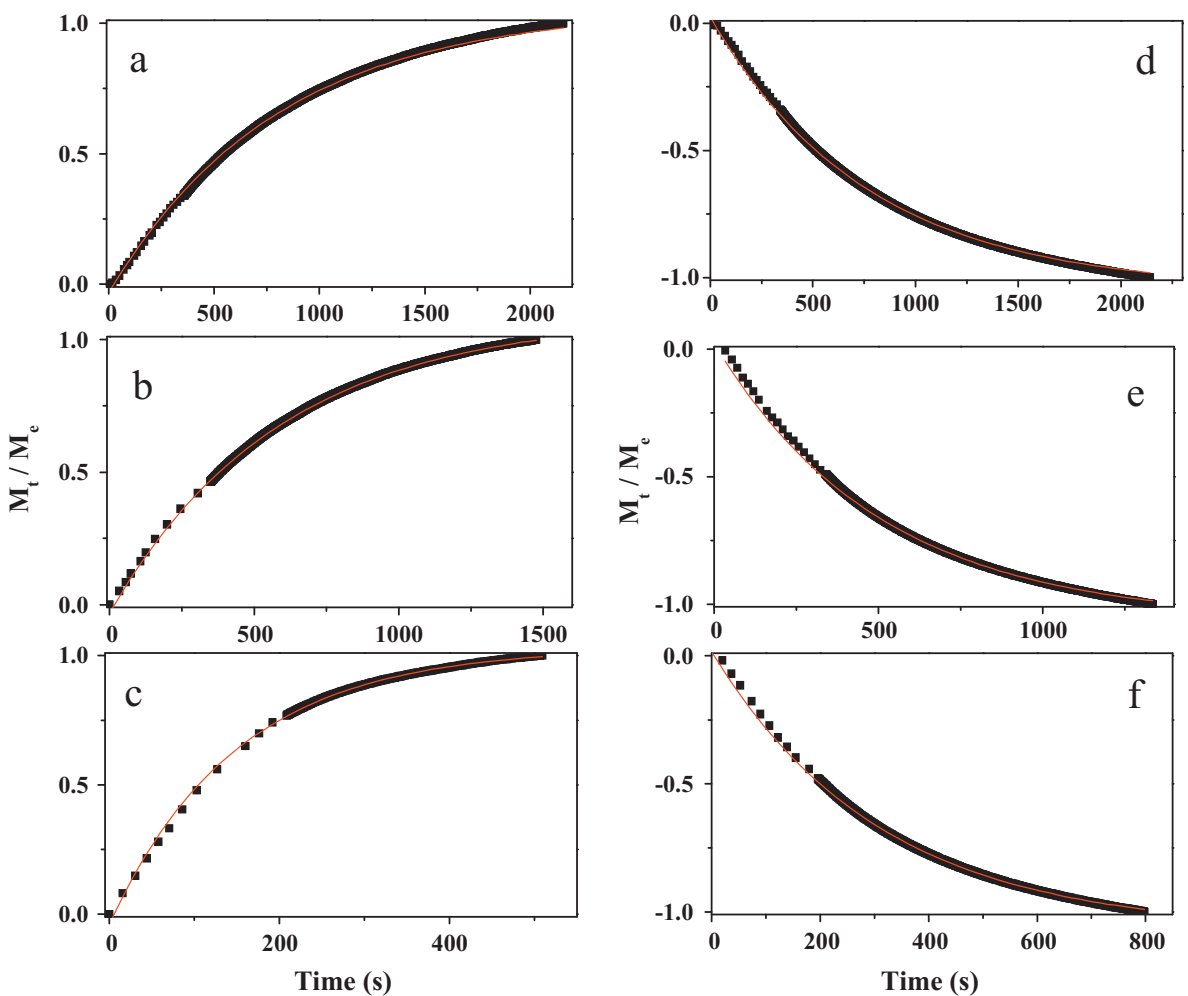

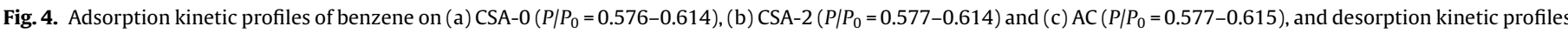
on (d) CSA-0 $\left(P / P_{0}=0.355-0.316\right)$, (e) CSA-2 $\left(P / P_{0}=0.435-0.395\right)$ and (f) AC $\left(P / P_{0}=0.395-0.356\right)$ at $35^{\circ} \mathrm{C}$, line is the LDF model.
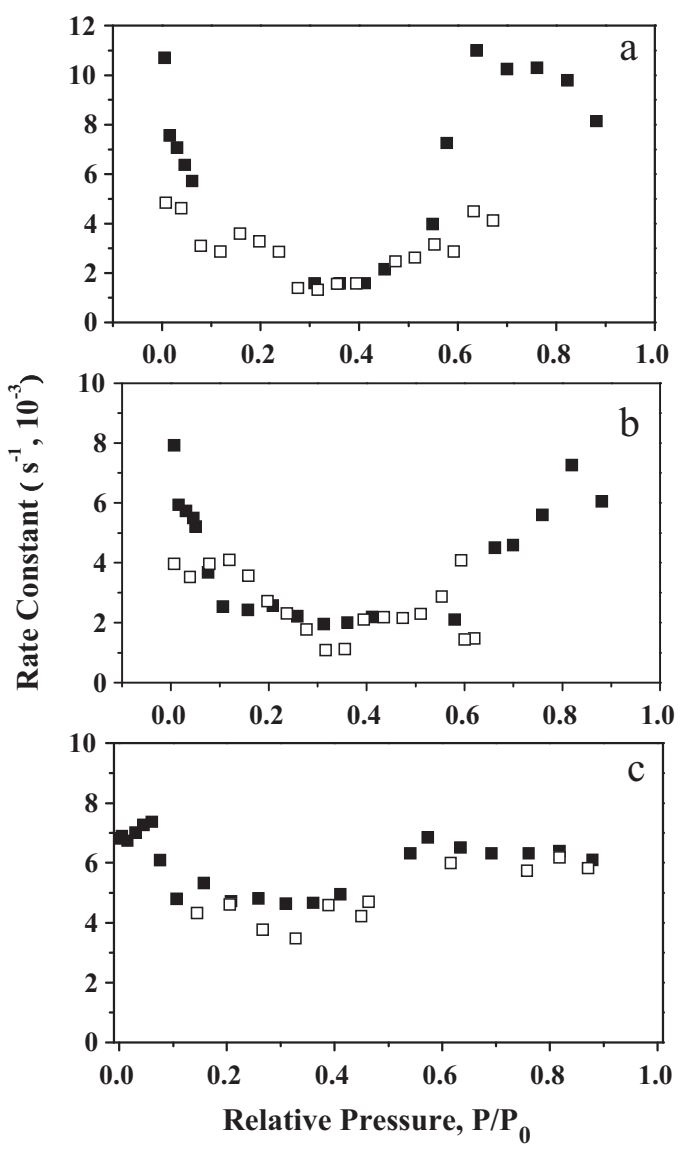

Fig. 5. Variation of rate constants for adsorption (filled symbols) and desorption (open symbols) of benzene with relative pressure on CSA-0, CSA-2, and AC at $35^{\circ} \mathrm{C}$. mesopores. In the case of desorption, the rate constants are similar to the adsorption for given pressure increments or decrements. Particularly, the rate constant for the final desorption step is much slower than that for the corresponding adsorption increment. This result is attributed to the difficulty in removing adsorbate from ultramicropores in adsorbents, which is caused by the overlap of potential fields from pore walls [34].

\subsection{Dynamic adsorption and desorption behaviors}

The investigations of dynamic adsorption and desorption were conducted for the removal of typical VOCs, such as benzene, by representative samples of CSA- 0, CSA- 2 and AC. A breakthrough measurement is a direct method designed to explore the dynamic performance of VOC adsorption at low concentrations [26]. The breakthrough curves of benzene adsorption under dry and wet conditions and the corresponding purge curves with nitrogen on CSA-0, CSA-2 and AC samples are shown in Fig. 6. Generally, longer breakthrough time results in higher dynamic adsorption capacity. The dynamic adsorption capacity $\left(Q^{\mathrm{a}}\right)$ was obtained by measuring the area between the maximum baseline and experimental curves, while the desorption capacity $\left(Q^{\mathrm{d}}\right)$ was obtained from the area between minimum baseline and experimental curve profiles [35]. The dynamic adsorption and desorption capacities of benzene on the CSA-0, CSA- 2 and AC are listed in Table 3.

In the adsorption region (Fig. 6a), all the samples exhibit slightly longer breakthrough time for benzene under dry condition as compared with that under wet condition (18\% RH). Correspondingly, Table 3 shows that the adsorption efficiency $\left(Q_{\text {wet }}^{\mathrm{a}} / Q_{\text {dry }}^{\mathrm{a}}\right)$ for all the samples is relatively high and the dynamic adsorption capacity under wet condition is about $85 \%$ of that under dry condition, suggesting the hydrophobic surface of adsorbents. It is obvious that AC represents the longest breakthrough time of benzene. However, the post-breakthrough curves of AC for benzene adsorption 


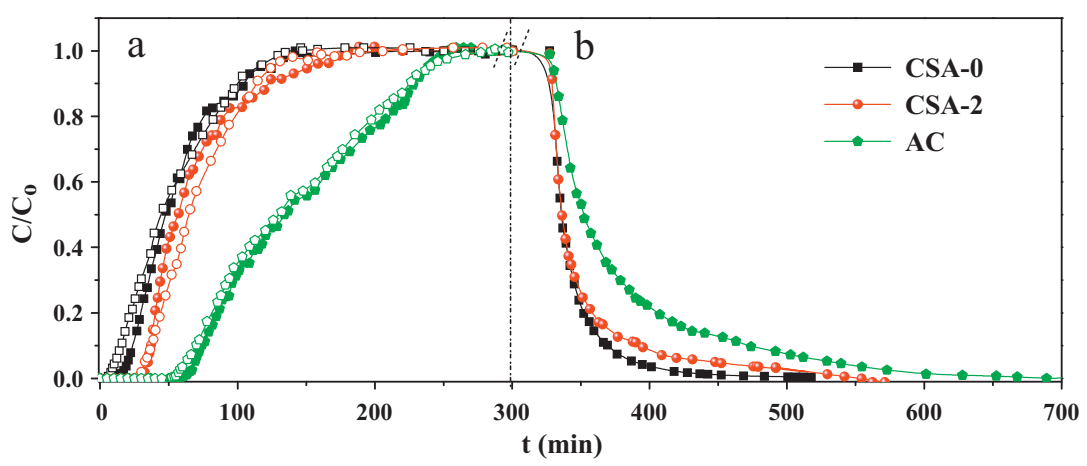

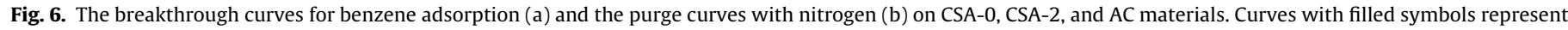
results obtained under dry conditions and curves with empty symbols represent results obtained under wet conditions (18\% $\mathrm{RH}$ ).

Table 3

Dynamic adsorption and desorption capacities of CSA-0, CSA-2 and AC.

\begin{tabular}{|c|c|c|c|c|c|}
\hline \multirow[t]{2}{*}{ Samples } & \multicolumn{3}{|c|}{ Dynamic adsorption capacity $Q^{\mathrm{a}}\left(\mathrm{mmol} \mathrm{g}^{-1}\right)$} & \multicolumn{2}{|c|}{ Dynamic desorption capacity $Q^{\mathrm{d}}\left(\mathrm{mmol} \mathrm{g}^{-1}\right)$} \\
\hline & $Q_{\text {dry }}^{a}$ & $Q_{\text {wet }}^{\mathrm{a}}$ & $Q_{\text {wet }}^{\mathrm{a}} / Q_{\mathrm{dry}}^{\mathrm{a}}(\%)$ & $\begin{array}{l}\text { Desorption by } \\
\text { purge } Q_{\text {purge }}^{d}\end{array}$ & $\begin{array}{l}\text { Desorption by } \\
\text { TPD } Q_{\text {TPD }}^{\mathrm{d}}\end{array}$ \\
\hline CSA-0 & 0.88 & 0.76 & 86 & 0.68 & 0.20 \\
\hline CSA-2 & 1.58 & 1.34 & 85 & 1.11 & 0.46 \\
\hline$A C$ & 3.99 & 3.41 & 85 & 1.86 & 2.12 \\
\hline
\end{tabular}

increase more gradually with time compared with the other two samples, implying significantly large mass transfer resistance in AC [26]. The dynamic adsorption capacity of benzene increases in the order of AC $>$ CSA-2 $>$ CSA-0 (Table 3), corresponding to the micropore volume of the adsorbents, which is consistent with the literature [26]. This result confirms that the presence of micropores in the adsorbents is an essential factor in determining the dynamic adsorption capacity. In contrast, the post-breakthrough sharpness of the increase in benzene concentration for CSA-0 and CSA-2 is more rapid, implying less diffusion resistance in the adsorbents during the adsorption process. The dynamic adsorption results indicate that the carbon-silica aerogel composite CSA-2 exhibits an excellent adsorption performance with higher dynamic adsorption capacity than silica aerogel CSA- 0 and less mass transfer resistance than microporous AC.

In the case of the purge region from Fig. $6 \mathrm{~b}$, the amount of benzene adsorbed on the external surface or relatively large pores of adsorbents can be desorbed during the nitrogen purge. The desorption breakthrough curve of $A C$ for benzene decreases more slowly than those of CSA- 0 and CSA-2. The VOC molecules weakly adsorbed on the external surface or the open mesopores of CSA- 0 and CSA- 2 adsorbents can be easily desorbed by purge gases. However, VOC molecules adsorbed in the micropores of AC are strongly held by adsorption forces and the strongly adsorbed molecules can resist the effects of purge gases.

Fig. 7 shows the TPD curves of benzene on CSA-0, CSA-2, and $\mathrm{AC}$ materials. The desorption peaks of benzene for TPD process at around $75^{\circ} \mathrm{C}$ for CSA- $0,80^{\circ} \mathrm{C}$ for CSA-2 and $105^{\circ} \mathrm{C}$ for AC were observed. Furthermore, the desorption peaks for CSA-0 and CSA-2 are significantly sharp, suggesting that the desorption of benzene molecules from CSA- 0 and CSA- 2 is fast. In contrast, the desorption peak for AC is broad, demonstrating that the desorption of VOCs from micropores in AC is slow. The temperature for complete elimination of residual VOCs from CSA- 0 and CSA- 2 is significantly lower than that from $A C$, and the decrease of temperature is very important from the practical point of energy saving. To test the reusability of the CSA composites, CSA- 2 was regenerated by thermal treatment at $120^{\circ} \mathrm{C}$ for $4 \mathrm{~h}$, and the regenerated adsorbent was subjected to adsorption/desorption cycles at least 7 times with-



Fig. 7. TPD curves of benzene on CSA-0, CSA-2, and AC materials.

out observing any appreciable loss in its adsorption capacity (see Fig. S3 in the Supporting Information).

\section{Conclusions}

In this study, carbon-silica aerogel composites were synthesized from cheap water glass precursors and granulated activated carbon. The hydrophobic surface of the CSA composites was obtained by post-synthesis modification with TMCS and subsequent ambient pressure drying procedure. The resultant CSA composites exhibit both microporous and mesoporous structures. As indicated by the static adsorption-desorption results, CSA composites have good affinity towards aromatic molecules and fast adsorption kinetics. The equilibrium adsorption capacity of benzene on CSA-2 $\left(5.06 \mathrm{mmol} \mathrm{g}^{-1}\right)$ is higher than that on AC $\left(4.37 \mathrm{mmol} \mathrm{g}^{-1}\right)$. The carbon-silica aerogel composite CSA-2 exhibits the best dynamic adsorption and desorption performance, because CSA-2 shows higher adsorption capacity than silica aerogel CAS-0 and less mass transfer resistance than AC. Furthermore, owing to the open mesostructure of CSA-2, the desorption of VOCS from CSA-2 by purge or TPD process is significantly faster than AC. With excellent adsorption and desorption performance, as potential adsorbents, the cost-effective CSA composites with hierarchical micro/mesoscopic structure could have a promising future in VOC emission controlling. 


\section{Acknowledgments}

This study was financially supported by the Special CoConstruction Project of Beijing Municipal Commission of Education, National Natural Science Foundation of China (20725723, 20807050), National Basic Research Program of China (2010CB732300).

\section{Appendix A. Supplementary data}

Supplementary data associated with this article can be found, in the online version, at doi:10.1016/j.jhazmat.2011.09.019.

\section{References}

[1] T. Yamamoto, S. Kataoka, T. Ohmori, Characterization of carbon cryogel microspheres as adsorbents for VOC, J. Hazard. Mater. 177 (2010) 331-335.

[2] M.E. Ramos, P.R. Bonelli, A.L. Cukierman, M.M.L. Ribeiro Carrott, P.J.M. Carrott, Adsorption of volatile organic compounds onto activated carbon cloths derived from a novel regenerated cellulosic precursor, J. Hazard. Mater. 177 (2010) $175-182$.

[3] R. Serna-Guerrero, A. Sayari, Applications of pore-expanded mesoporous silica. 7. Adsorption of volatile organic compounds, Environ. Sci. Technol. 41 (2007) 4761-4766.

[4] N. Mohan, G.K. Kannan, S. Upendra, R. Subha, N.S. Kumar, Breakthrough of toluene vapours in granular activated carbon filled packed bed reactor, J. Hazard. Mater. 168 (2009) 777-781.

[5] K.J. Kim, C.S. Kang, Y.J. You, M.C. Chung, M.W. Woo, W.J. Jeong, N.C. Park, H.G Ahn, Adsorption-desorption characteristics of VOCs over impregnated activated carbons, Catal. Today 111 (2006) 223-228.

[6] D. Das, V. Gaur, N. Verma, Removal of volatile organic compound by activated carbon fiber, Carbon 42 (2004) 2949-2962.

[7] W.G. Shim, J.W. Lee, H. Moon, Adsorption equilibrium and column dynamics of VOCs on MCM-48 depending on pelletizing pressure, Micropor. Mesopor. Mater. 88 (2006) 112-125.

[8] P. Liu, C. Long, Q. Li, H. Qian, A. Li, Q. Zhang, Adsorption of trichloroethylene and benzene vapors onto hypercrosslinked polymeric resin, J. Hazard. Mater. 166 (2009) 46-51.

[9] M. Moner-Girona, E. Martinez, J. Esteve, A. Roig, R. Solanas, E. Molins, Micromechanical properties of carbon-silica aerogel composites, Appl. Phys. A: Mater. 74 (2002) 119-122.

[10] A. Venkateswara Rao, N.D. Hegde, H. Hirashima, Absorption and desorption of organic liquids in elastic superhydrophobic silica aerogels, J. Colloid Interface Sci. 305 (2007) 124-132.

[11] S. Standeker, Z. Novak, Z. Knez, Adsorption of toxic organic compounds from water with hydrophobic silica aerogels, J. Colloid Interface Sci. 310 (2007) 362-368.

[12] S.J. Coleman, P.R. Coronado, R.S. Maxwell, J.G. Reynolds, Granulated activated carbon modified with hydrophobic silica aerogel-potential composite materials for the removal of uranium from aqueous solutions, Environ. Sci. Technol. 37 (2003) 2286-2290.

[13] H. El Rassy, P. Buisson, B. Bouali, A. Perrard, A.C. Pierre, Surface characterization of silica aerogels with different proportions of hydrophobic groups, dried by the $\mathrm{CO}_{2}$ supercritical method, Langmuir 19 (2003) 358-363.

[14] P.R. Aravind, P. Mukundan, P. Krishna Pillai, K.G.K. Warrier, Mesoporous silica-alumina aerogels with high thermal pore stability through hybrid sol-gel route followed by subcritical drying, Micropor. Mesopor. Mater. 96 (2006) 14-20.

[15] F. Shi, L. Wang, J. Liu, Synthesis and characterization of silica aerogels by a novel fast ambient pressure drying process, Mater. Lett. 60 (2006) 3718-3722.
[16] L. Zhou, X. Liu, J. Li, Y. Sun, Y. Zhou, Sorption/desorption equilibrium of methane in silica gel with pre-adsorption of water, Colloids Surf. A 273 (2006) 117-120.

[17] C.A. Morris, M.L. Anderson, R.M. Stroud, C.I. Merzbacher, D.R. Rolison, Silica sol as a nanoglue: flexible synthesis of composite aerogels, Science 284 (1999) 622.

[18] M.L. Anderson, R.M. Stroud, D.R. Rolison, Enhancing the activity of fuelcell reactions by designing three-dimensional nanostructured architectures: Catalyst-modified carbon-silica composite aerogels, Nano Lett. 2 (2002) 235-240.

[19] K. Fujiki, T. Ogasawara, N. Tsubokawa, Preparation of a silica gel-carbon black composite by the sol-gel process in the presence of polymer-grafted carbon black, J. Mater. Sci. 33 (1998) 1871-1879.

[20] P.B. Sarawade, J.K. Kim, H.K. Kim, H.T. Kim, High specific surface area TEOSbased aerogels with large pore volume prepared at an ambient pressure, Appl. Surf. Sci. 254 (2007) 574-579.

[21] B. Dou, J. Li, Q. Hu, C. Ma, C. He, P. Li, Z. Hao, S. Qiao, Hydrophobic micro/mesoporous silica spheres assembled from zeolite precursors in acidic media for aromatics adsorption, Micropor. Mesopor. Mater. 133 (2010) $115-123$.

[22] K.S.W. Sing, D.H. Everett, R.A.W. Haul, L. Moscou, R.A. Pierotti, J. Rouquérol, T. Siemieniewska, Reporting physisorption date for gas/solid systems with special referance to the determination of surface area and porosity, Pure Appl. Chem. 57 (1985) 603-619.

[23] Q. Huang, H. Vinh-Thang, A. Malekian, M. Ei, D. Trong-On, S. Kaliaguine, Adsorption of n-heptane, toluene and o-xylene on mesoporous UL-ZSM5 materials, Micropor. Mesopor. Mater. 87 (2006) 224-234.

[24] P. Tien, L.K. Chau, Novel sol-gel-derived material for separation and optica sensing of metal ions: Propyl-ethylenediamine triacetate functionalized silica, Chem. Mater. 11 (1999) 2141-2147.

[25] A.P. Rao, A.V. Rao, G.M. Pajonk, Hydrophobic and physical properties of the ambient pressure dried silica aerogels with sodium silicate precursor using various surface modification agents, Appl. Surf. Sci. 253 (2007) 6032-6040.

[26] K. Kosuge, S. Kubo, N. Kikukawa, M. Takemori, Effect of pore structure in mesoporous silicas on VOC dynamic adsorption/desorption performance, Langmuir 23 (2007) 3095-3102.

[27] X. Lin, A.J. Blake, C. Wilson, X.Z. Sun, N.R. Champness, M.W. George, P. Hubberstey, R. Mokaya, M. Schroder, A porous framework polymer based on a Zinc (II) 4,4-Bipyridine-2,6,2,6-tetracarboxylate: synthesis, structure, and zeolite-like behaviors, J. Am. Chem. Soc. 128 (2006) 10745-10753.

[28] D. Ramirez, S. Qi, M.J. Rood, K.J. Hay, Equilibrium and heat of adsorption for organic vapors and activated carbons, Environ. Sci. Technol. 39 (2005) 5864-5871.

[29] H. Vinh-Thang, Q. Huang, M. Eic, D. Trong-On, S. Kaliaguine, Adsorption of C7 hydrocarbons on biporous SBA-15 mesoporous silica, Langmuir 21 (2005) 5094-5101.

[30] A.J. Fletcher, Y. Yüzak, K.M. Thomas, Adsorption and desorption kinetics for hydrophilic and hydrophobic vapors on activated carbon, Carbon 44 (2006) 989-1004.

[31] A.J. Fletcher, E.J. Cussen, T.J. Prior, M.J. Rosseinsky, C.J. Kepert, K.M. Thomas, Adsorption dynamics of gases and vapors on the nanoporous metal organic framework material $\mathrm{Ni}_{2}(4,4 \text { '-bipyridine })_{3}\left(\mathrm{NO}_{3}\right)_{4}$ : guest modification of host sorption behavior, J. Am. Chem. Soc. 123 (2001) 10001-10011.

[32] C.R. Reid, K.M. Thomas, Adsorption kinetics and size exclusion properties of probe molecules for the selective porosity in a carbon molecular sieve used for air separation, J. Phys. Chem. B 105 (2001) 10619-10629.

[33] A. Berenguer-Murcia, A.J. Fletcher, J. Garcia-Martinez, D. Cazorla-Amoros, A Linares-Solano, K.M. Thomas, Probe molecule kinetic studies of adsorption on MCM-41, J. Phys. Chem. B 107 (2003) 1012-1020.

[34] L. Cossarutto, T. Zimny, J. Kaczmarczyk, T. Siemieniewska, J. Bimer, J.V. Weber, Transport and sorption of water vapour in activated carbons, Carbon 39 (2001) 2339-2346.

[35] W. Song, R.E. Justice, C.A. Jones, V.H. Grassian, S.C. Larsen, Synthesis, characterization, and adsorption properties of nanocrystalline ZSM-5, Langmuir 20 (2004) 8301-8306. 